\title{
EXPERIMENTAL STUDY OF THE BENDING STRENGTH OF RECYCLED CONCRETE AND WOODEN WASTE BY HEATING COMPACTION
}

\author{
Li Liang $^{l}$ and Yuya Sakai ${ }^{2}$ \\ ${ }^{1}$ Master's Student, School of Architecture and the Built Environment, KTH Royal Institute of Technology, lianli@kth.se. \\ ${ }^{2}$ Assistant Professor, Institute of Industrial Science, The University of Tokyo, ysakai@iiis.u-tokyo.ac.jp
}

\begin{abstract}
A large amount of concrete waste is generated around the world and its recycling is an urgent issue. In this research, a new approach to recycle concrete waste with wooden waste was studied. Concrete and wooden wastes were crushed, mixed, and heat compacted to produce plates with different water contents and mix proportions at various temperatures, pressures, and durations of compaction. The bending strength of the plates was measured after compaction. The result indicated that with an increase in the percentage of wooden waste in the mixture, pressure, or temperature improved the bending strength. The increase in water content reduced the bending strength. Most of the products exhibited higher bending strength than that of ordinary concrete.
\end{abstract}

Keywords: Recycling, Concrete waste, Wooden waste, Heating compaction, Bending strength

Li Liang, Master's, Civil Eng.

School of Architecture and Built Environment

KTH Royal Institute of Technology.

SE-100 44 Stockholm

Sweden

Email: lianli@kth.se

Tel: +818025685358 


\section{INTRODUCTION}

Concrete is a widely used primary construction material in most construction projects, which leads to significant amounts of concrete waste. Most of the concrete waste is used as backfill material for landfilling and road bases. Some of the concrete waste is recycled as an aggregate in casting new concrete [1]. While the demand for backfill material is decreasing in developed countries and the reuse as aggregate for concrete production requires more cement, the result is unsustainable as the production of cement results in significant amounts of carbon dioxide emission. Establishing a more sustainable method to recycle concrete waste is an urgent requirement.

Previous studies have shown that the total porosity (which is defined as the total volume of the overall volume of pores larger than gel pores) is the primary factor influencing the strength of cement paste [2]. The hardness and modulus of elasticity of the hydrated Portland cement compacts appeared to be the same as that of original cement paste before crushing and compacting when the total pore volume was the same [3]. Therefore, powder compaction was proposed as a sustainable way to recycle concrete waste [4]. Studies on recycling concrete waste by powder compaction suggest that the required compaction pressure for this method is quite high to achieve the applicable strength in construction [5]. Therefore, creating more favourable conditions for recycling concrete waste is essential. Meanwhile, most of the wooden waste is burned and some of it is recycled as robust boards by heat-pressing [6], because lignin in the wood melts from heat, fills the gaps, and functions as glue. Lignin can also possibly function as glue to bond concrete waste powder when concrete and wooden wastes are mixed and heatpressed.

The objective of this study was to understand the effect of different production conditions on the bending strength of recycled concrete waste by heat compaction with wooden waste. The conditions studied in this paper include the mix proportion, pressure, temperature, pressing duration, and water content. The change in condition factors caused the bending strength of the recycled products to vary between 0 and $50 \mathrm{MPa}$. The samples were evaluated based on the bending strength and their colour and optimum production conditions to recycle concrete waste with wooden waste were discussed.

\section{METHOD}

\subsection{Materials}

The concrete waste powder was prepared by crushing and milling the concrete samples with water to cement ratio of $0.45-0.55$. The powder was milled until it passed through a $0.3 \mathrm{~mm}$ sieve. The wooden waste was Japanese cedar and was crushed until it passed through a $0.5 \mathrm{~mm}$ sieve. The water content of the wooden waste was $10 \%$ and was calculated by dividing the difference between the original mass and the mass after drying at $105{ }^{\circ} \mathrm{C}$. In this experiment, the compacted concrete waste samples with different water content (10-100\%) of wooden waste were tested.

\subsection{Compaction}

Samples of $5 \times 45 \times 65 \mathrm{~mm}$ were produced using a hydraulic pressing machine under temperatures of $160-220^{\circ} \mathrm{C}$ and pressures of $10-50 \mathrm{MPa}$ for a duration of 1-30 min. A steel mould was placed on the steel heating plate and the mixture of concrete and wooden waste powder was filled into the steel mould (Figure 1). The mix proportions of concrete and wood by mass were 3:1, 2:1, 1:1, 1:2, and 1:3. The pressure was maintained for the designed compaction duration. Samples under different conditions are showed in Figure 2. The experiments were conducted under the condition of 1:1 mixture proportion of concrete and wooden wastes, $10 \%$ moisture content of wood waste, and heat pressing at $180{ }^{\circ} \mathrm{C}$ and 50 MPa for $5 \mathrm{~min}$, unless otherwise noted. To reduce influence of error and variation, under each condition three samples were produced. Result shows the average value of bending strength of the samples under each condition. 


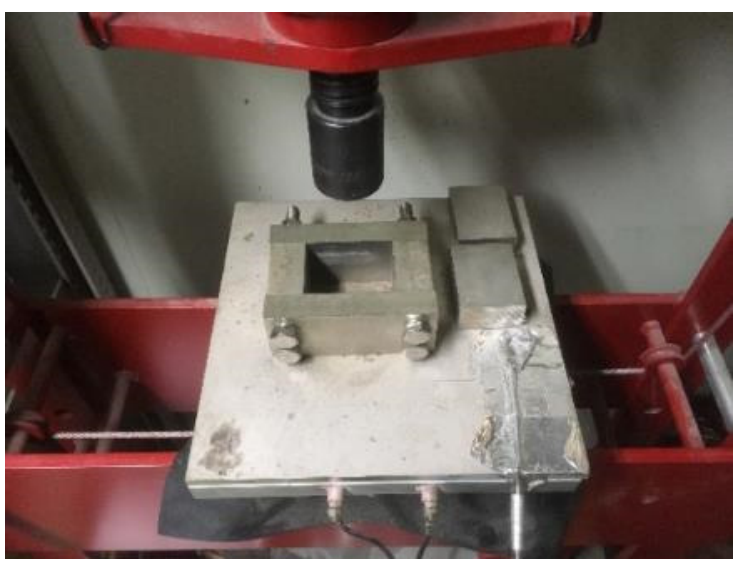

Figure 1. Setup for heating pressing

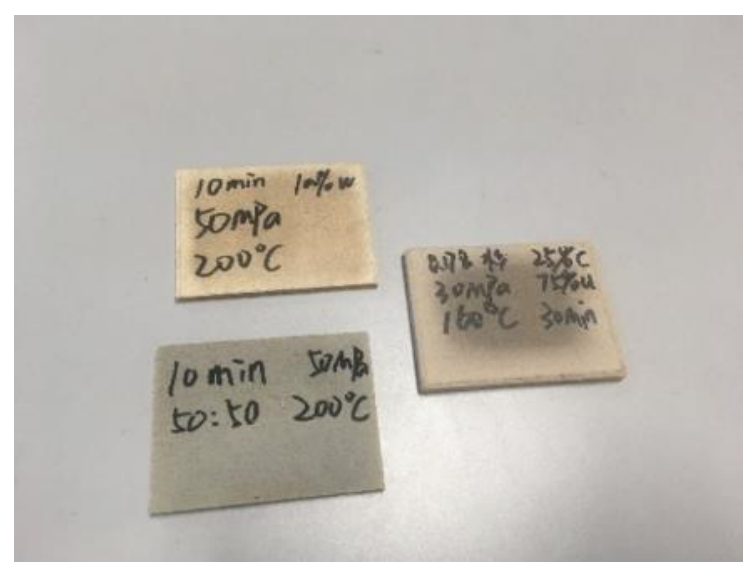

Figure 2. Samples prepared under different conditions

\subsection{Bending strength test}

The bending strength of the samples was tested using a universal testing machine (Figure. 3).

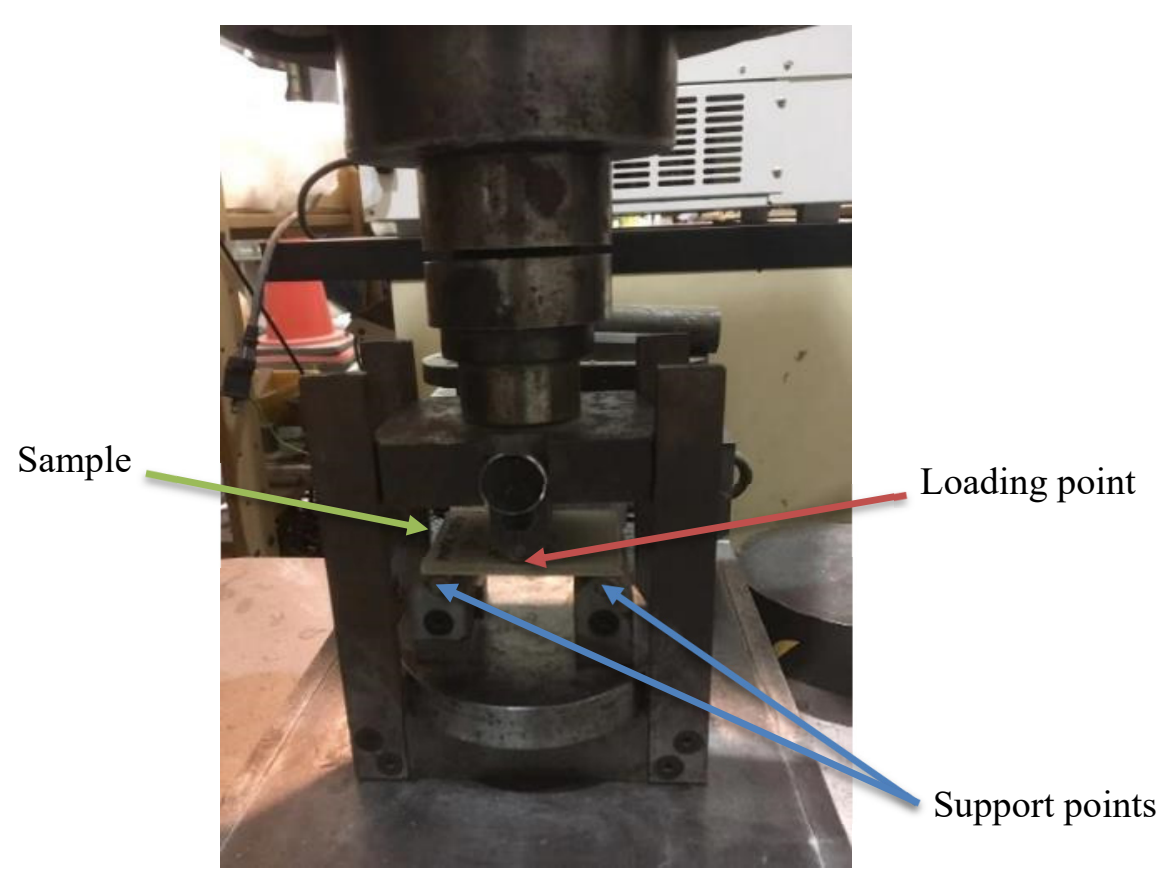

Figure 3. Bending strength test setup

The peak force was regarded as the loading capacity of the samples. Bending strength can be calculated using the peak force and the distance between the two supports (50 $\mathrm{mm}$ in this study):

$$
R=(3 F \cdot L) /\left(2 W \cdot t^{2}\right)
$$

where $R$ is the bending strength of sample (MPa), $F$ is the peak force obtained from the universal testing machine $(\mathrm{N}), L$ is loading distance (which is the distance between two supports $(\mathrm{mm})$ ), $W$ is the width of the sample (mm), and $t$ is the thickness of the sample $(\mathrm{mm})$. 


\section{RESULTS AND DISCUSSION}

\subsection{The effect of compaction duration}

The effect of compaction duration on the bending strength and density is shown in Figure 4. The sample of 1 min compaction duration exhibited the lowest bending strength. When the compaction duration was increased to $5 \mathrm{~min}$, the bending strength also increased. When the compaction duration was longer than $5 \mathrm{~min}$, the bending strength was almost constant though there is slight decrease and increase. This indicated that the production of this recycled product required a certain compaction duration and $5 \mathrm{~min}$ was enough for the compaction adopted in this test. There are increase and decrease in the density and these corresponds to the trend of the bending strength. This correspondence indicates that the density is one of the important factor that governs the bending strength of the product.
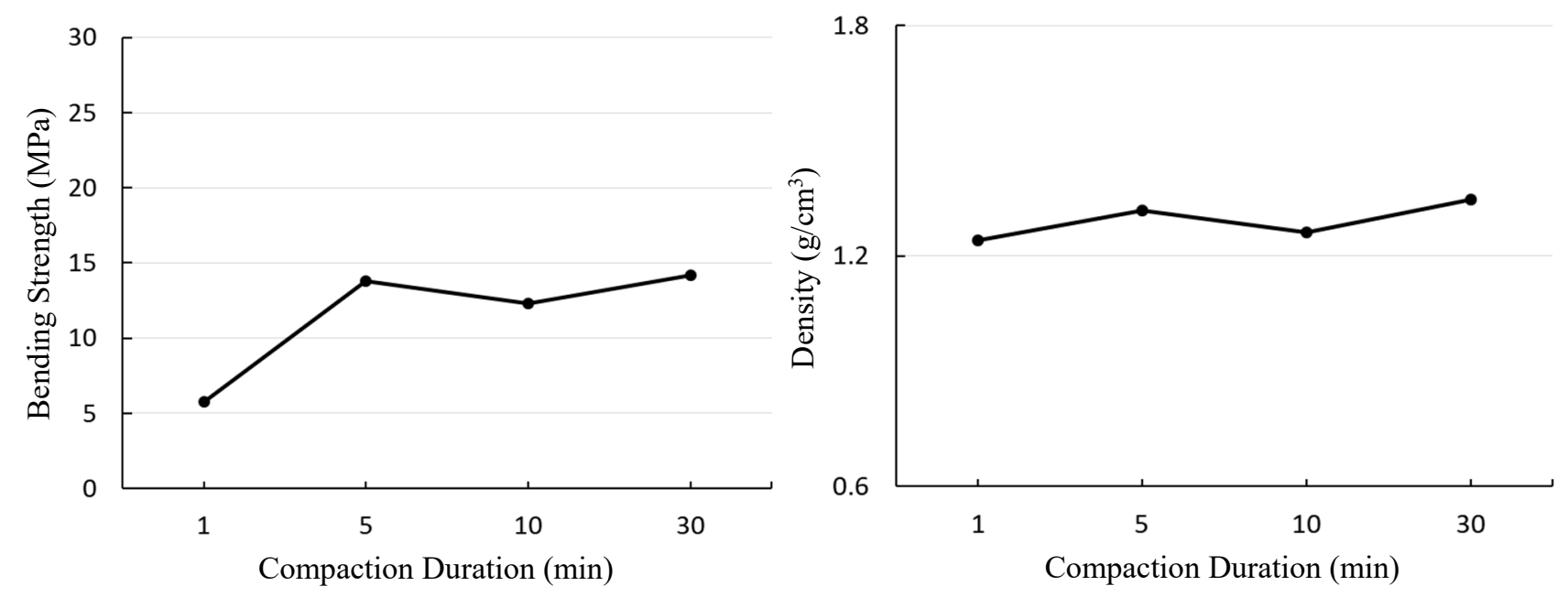

Figure 4. Bending strength and density under different compaction durations

The appearances of the four samples are shown in Figure 5 and they did not exhibit any clear differences. The sample with the longer compaction duration exhibited a slightly darker colour. The textures were also similar.

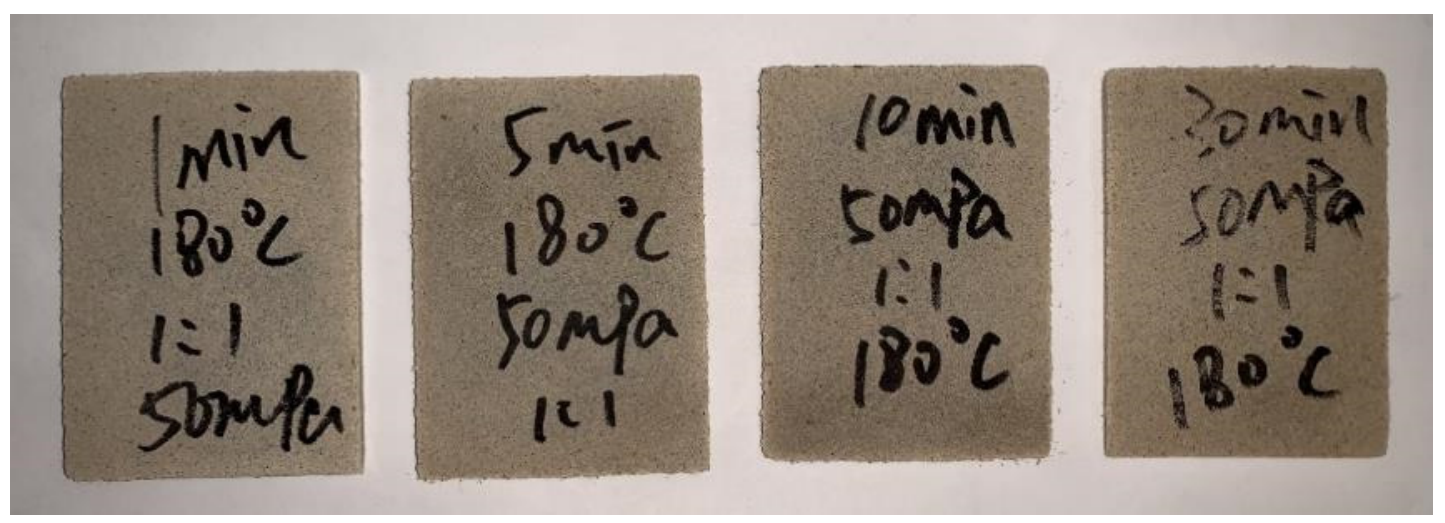

Figure 5. Samples of $50 \mathrm{MPa}, 180{ }^{\circ} \mathrm{C}, 10 \%$ water content, $1: 1$ mixture proportion of concrete to wood, different duration $(1,5,10$, and $30 \mathrm{~min}$ from left to right) 


\subsection{The effect of mixture proportion}

The effect of mixture proportion on the bending strength is shown in Figure 5. The overall trend in the variation of the bending strength with the mixture proportion was that the bending strength improved substantially with the percentage increase of wooden waste. This demonstrates that the wooden powder had a significant effect in improving the bending strength of the recycled product. In other words, the increase in concrete percentage reduced the bending strength. While the purpose of this experiment was mainly to recycle concrete waste, a balanced proportion of concrete waste and wooden powder was required so that the bending strength of the recycled products can satisfy the requirements for applications in construction projects where the percentage of concrete waste is relatively high. There is a significant strength reduction when the mass ratio of concrete to wood is larger than $1: 1$. As the percentage of wooden waste increased, the density decreased. This was expected because the density of the wooden substance is smaller than that of concrete waste powder.
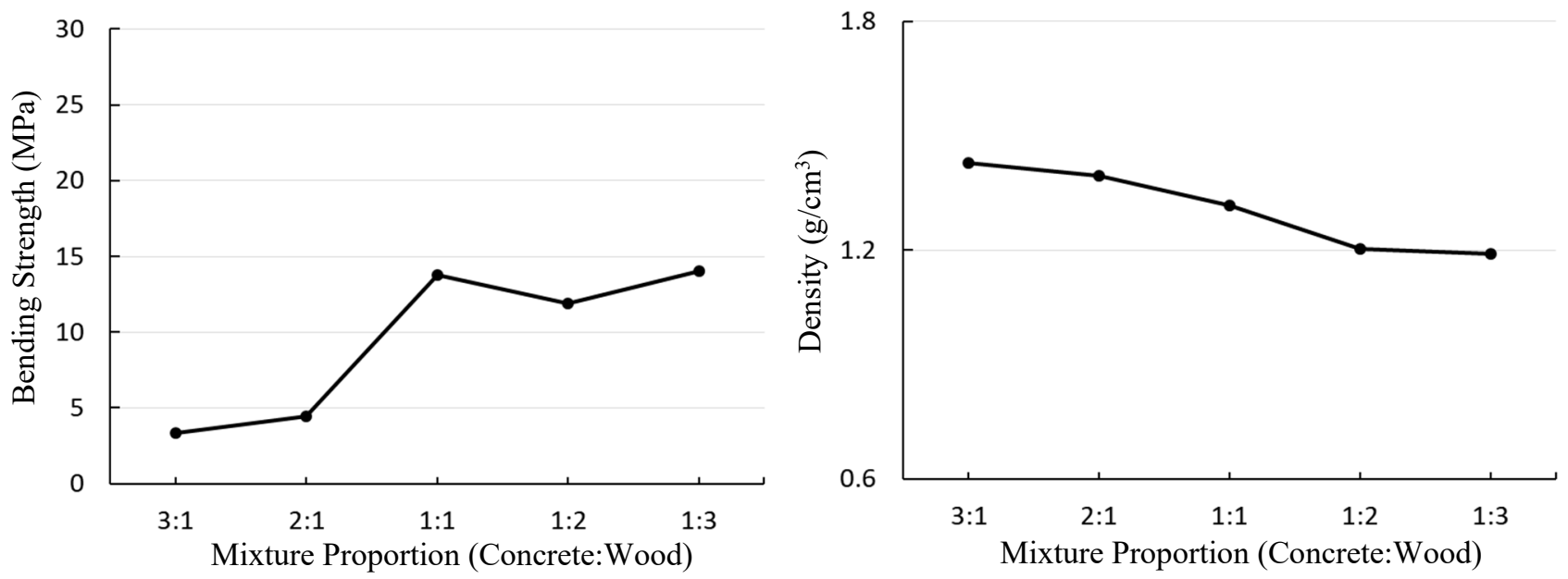

Figure 6. Bending strength and density under different mixture proportion

The appearances of the samples are shown in Figure 7. The texture was similar for all samples. Clear differences were observed in colour; as the percentage of wooden waste increased, the colour turned yellow from grey.

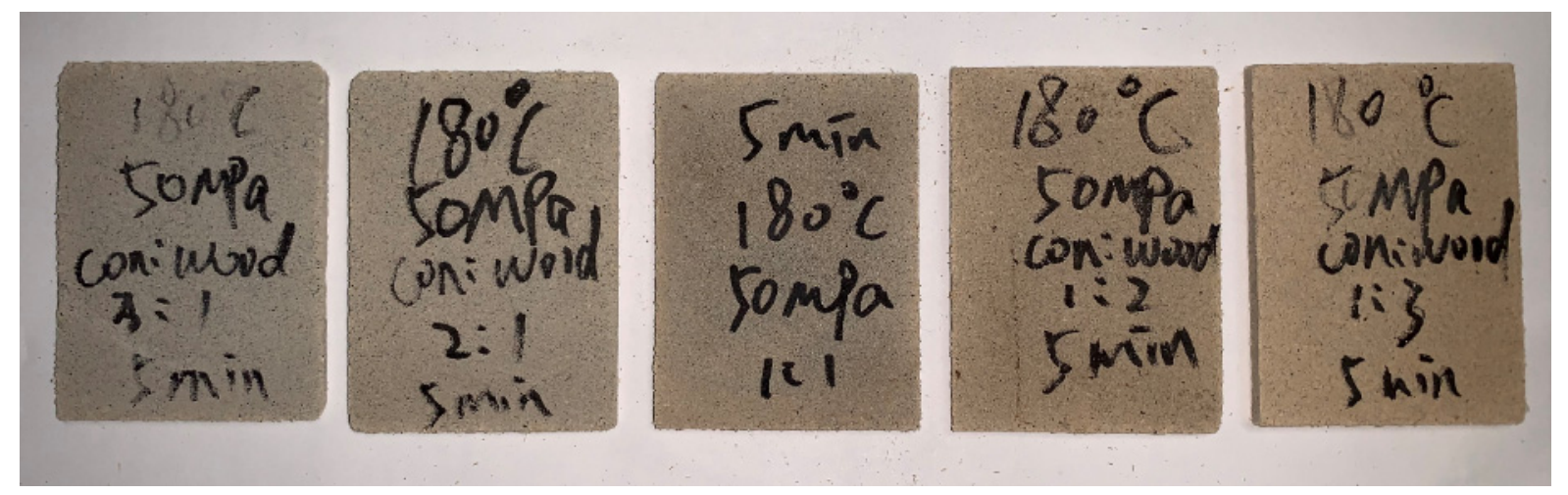

Figure 7. Samples of $50 \mathrm{MPa}, 180{ }^{\circ} \mathrm{C}, 10 \%$ water content, 5 min compaction duration, and different mixture proportions of concrete to wood $(3: 1,2: 1,1: 1,1: 2,1: 3$ from left to right) 


\subsection{The effect of temperature}

The effect of temperature on the bending strength is shown in Figure 8. Samples were produced under the condition of 1:3 and 1:1 mixture proportions and temperatures at $160,180,200$, and $220^{\circ} \mathrm{C}$. The bending strength increased with compaction temperature. The bending strength of $1: 3$ mixture proportion increased significantly with temperature, while the increment in the 1:1 mixture proportion increased slightly. The density followed a similar trend with bending strength. This difference indicated that the temperature affected the deformation of the wood powder and not the concrete powder. The obtained result indicated that the increase in temperature improved the bending strength by reducing the porosity in the recycled products. This was probably because under high temperatures, the melting of lignin would be accelerated and it would fill more pores between particles [7]. This phenomenon is the reason the bending strength increased with temperature.
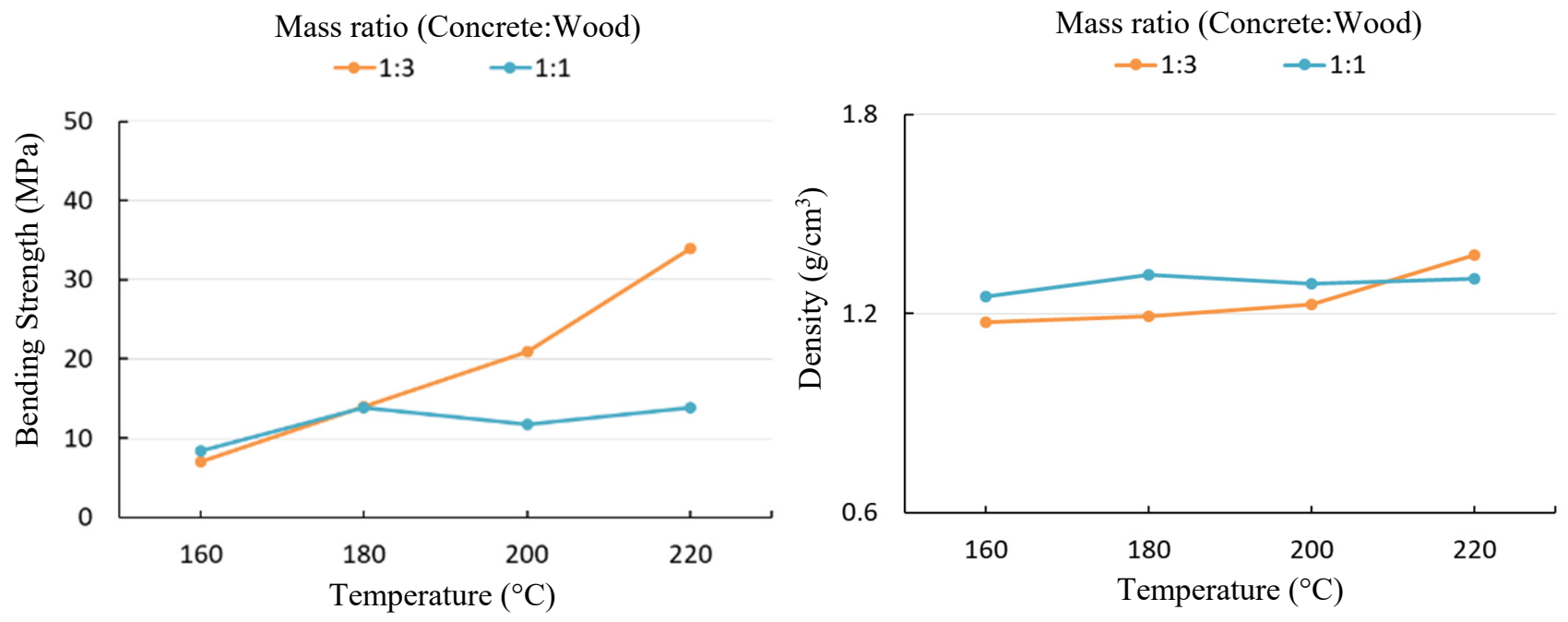

Figure 8. Bending strength and density under different temperatures

The appearances of the samples under different temperatures are shown in Figure 9. As the compaction temperature increased, the colour turned black like char. The texture became finer.

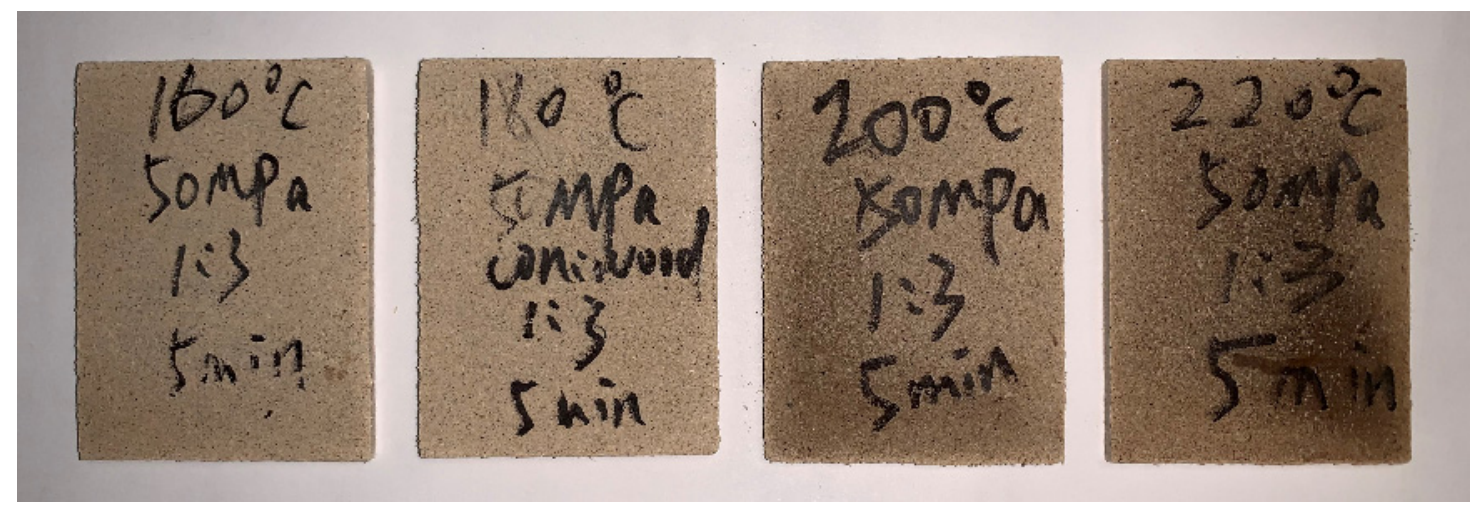

Figure 9. Samples of $50 \mathrm{MPa}, 10 \%$ water content, 1:3 mixture proportion of concrete to wood, $5 \mathrm{~min}$ compaction duration, and different temperatures $\left(160^{\circ} \mathrm{C}, 180^{\circ} \mathrm{C}, 200^{\circ} \mathrm{C}\right.$, and $220^{\circ} \mathrm{C}$ from left to right) 


\subsection{The effect of water content}

The effect of water content on the bending strength is shown in Figure 10. Samples were produced under the conditions of $1: 3$ and $1: 1$ mixture proportions, pressing temperature of $220{ }^{\circ} \mathrm{C}$, and water content of $10,30,50$, and $100 \%$. The bending strength was observed to decrease with increasing water content. The bending strength of 1:3 mixture proportion decreased significantly, while the increment in 1:1 mixture proportion decreased slightly. This difference indicated that the water content affected the matrix of the wood powder and not the concrete powder. The variation in density displayed a similar trend with the bending strength. The obtained result indicated that the increment in water content reduced the bending strength. The following is a possible explanation of this reduction: under high temperature and steam environment, wood powder was subjected to thermo-hydro-process. Due to this heat treatment, bending strength of wood material reduced [8].
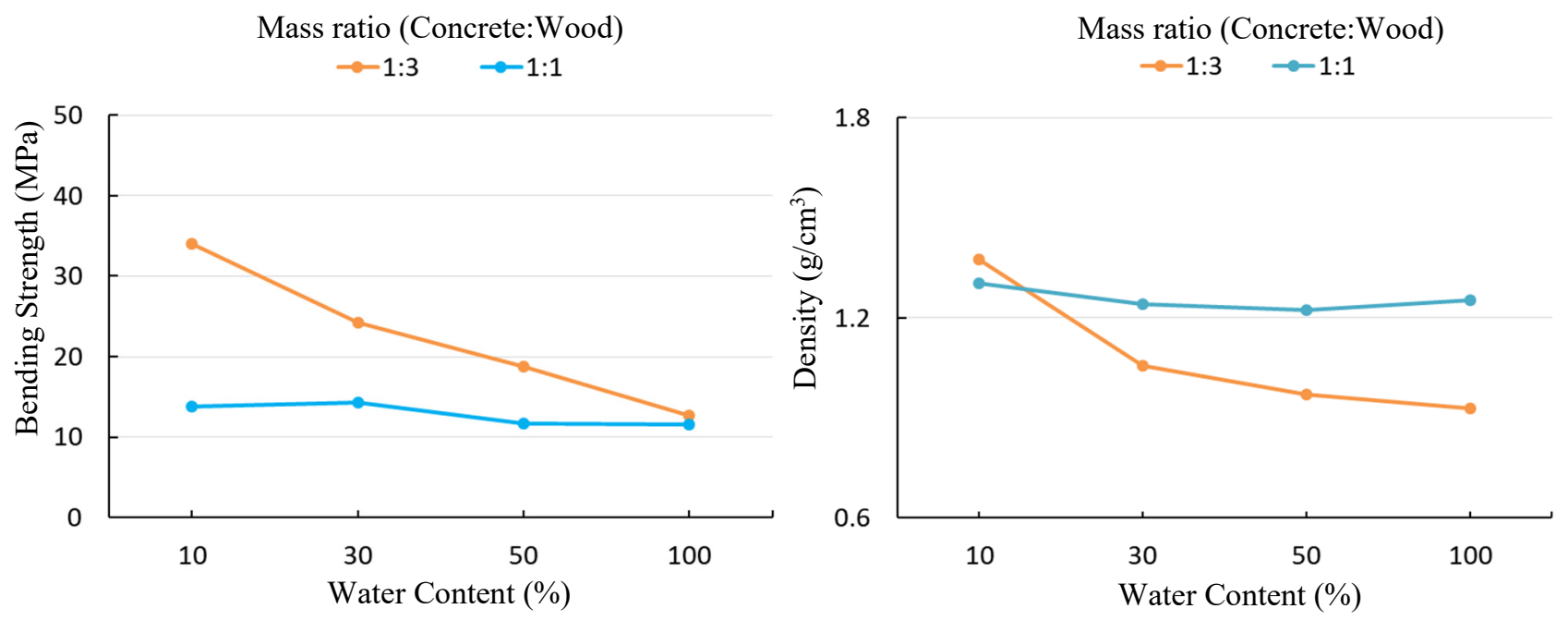

Figure 10. Bending strength and density under different water content

The appearances of the samples with different water content exhibited differences in colour and texture as shown in Figure 11. As the water content increased, the black area in the middle expanded. The texture of this black area was smooth. The black area was formed under high temperature and steam environment probably as a result of the thermo-hydro-process of wood powder [9].

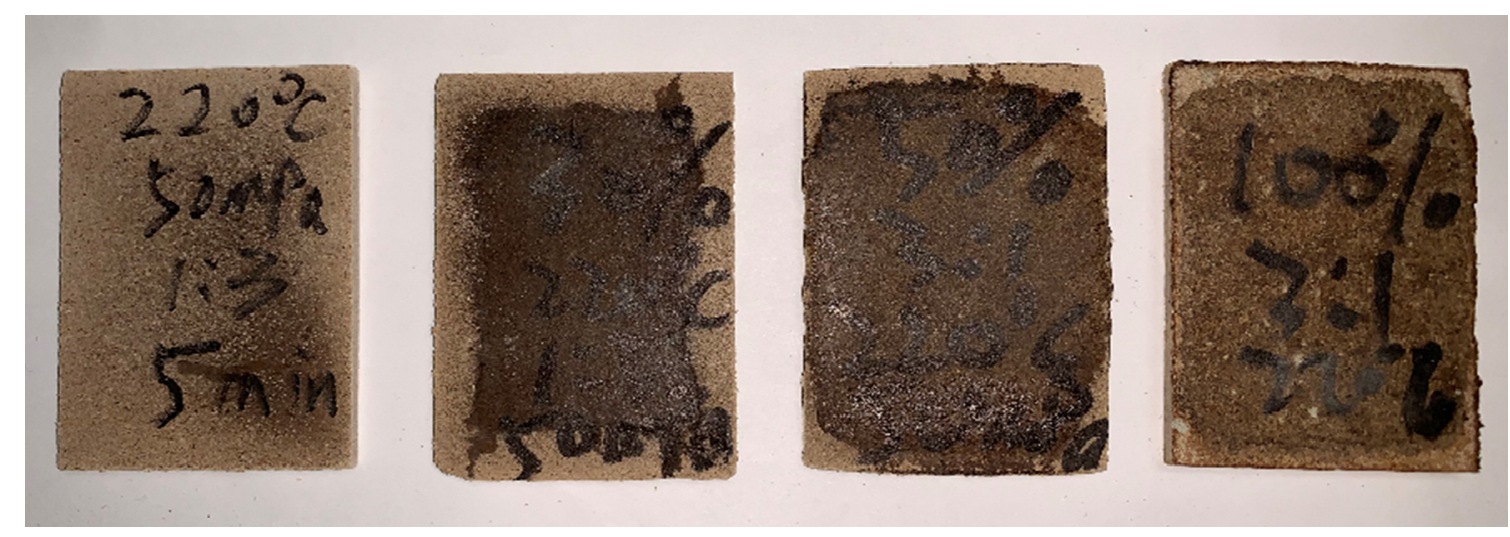

Figure 11. Samples of $50 \mathrm{MPa}, 220^{\circ} \mathrm{C}, 1: 3$ mixture proportion of concrete to wood, 5 min compaction duration, and different water content $(10,30,50$, and $100 \%$ from left to right) 


\subsection{The effect of pressure}

The effect of pressure on the bending strength is shown in Figure 12. Samples were produced under the conditions of $1: 1$ and $1: 3$ mixture proportion, $220^{\circ} \mathrm{C}$, and pressure of $10,20,30$, and $50 \mathrm{MPa}$. As the pressure increased, the bending strength of both mixture proportions increased remarkably. The variation in density indicated the similar trend in bending strength. A possible explanation is that pressing with higher pressure accelerated compaction and also the flow of lignin filling the pores, decreased the porosity, and, as a result, the strength of the samples increased.
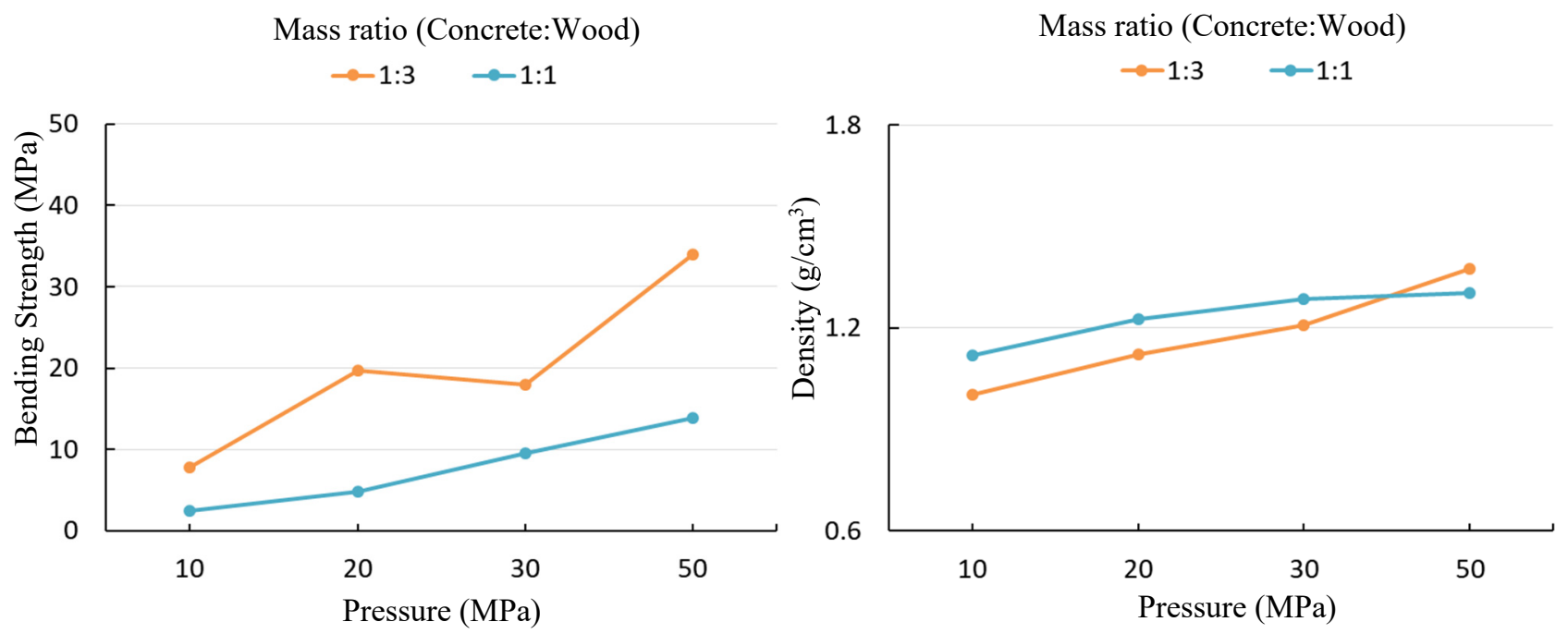

Figure 12. Bending strength under different pressures

The appearances of the samples under different pressures are shown in Figure 13. Clear differences in colour were observed. As the pressure increased, the colour turned darker and the texture became finer.

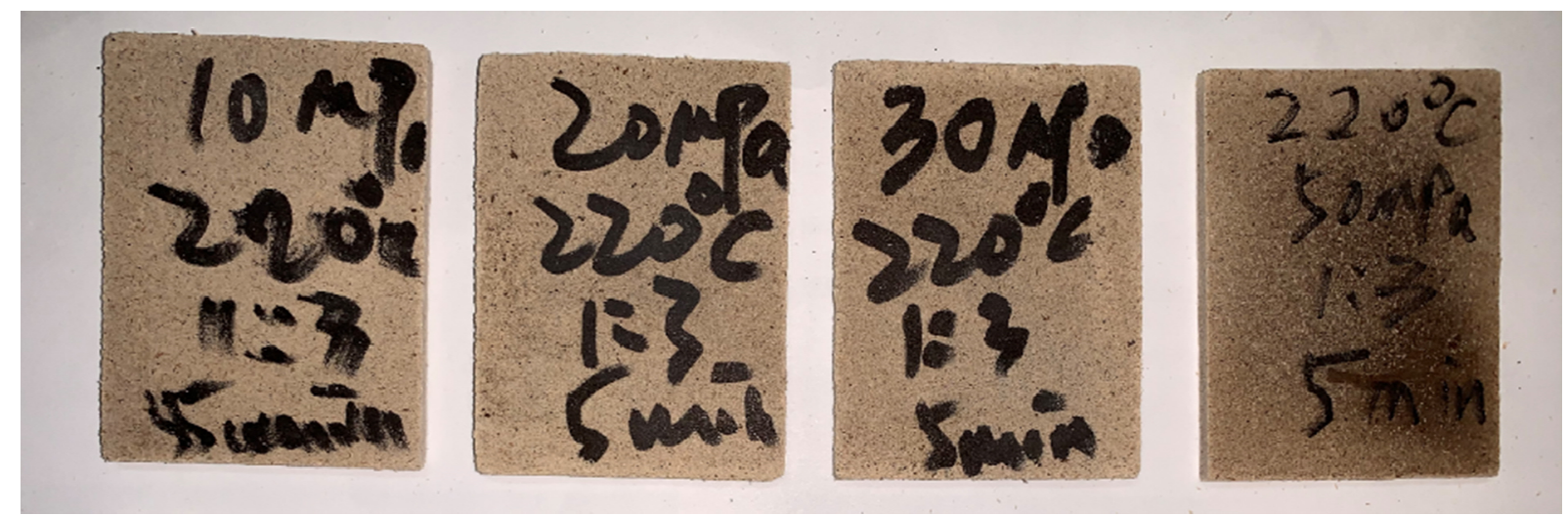

Figure 13. Samples of $220^{\circ} \mathrm{C}, 10 \%$ water content, $1: 3$ mixture proportion of concrete to wood, $5 \mathrm{~min}$ compaction duration, and different pressures $(10,20,30$, and $50 \mathrm{MPa}$ from left to right)

As shown, most of the products exhibited higher bending strength than that of ordinary concrete ( approximately $5 \mathrm{MPa}$ ). Further experiments of different conditions and variables are expected to be conducted to observe the dependency of each production condition factors and to simplify the production condition of this recycling method. 


\section{CONCLUSIONS}

This experimental study examined the effect of production condition factors on the bending strength of recycled concrete waste by heat compaction with wooden waste. The obtained results are summarized as follows:

(1) When the percentage of wooden waste declines, the effect of temperature, water content, and pressure become less evident, indicating that these factors affect the wood powder and not the concrete.

(2) The increase in the compaction duration, pressure, or temperature improves the bending strength of the products within a certain range. This is probably because the flow of lignin in wood powder is accelerated and more pores are filled by lignin.

(3) The increase in the mixture percentage of wooden waste improves the bending strength of the recycled products. The increase in water content creates a smoother texture but reduces the bending strength.

(4) Most of the products exhibited higher bending strength than that of ordinary concrete.

\section{ACKNOWLEDGMENTS}

The experimental works in this paper is a corroborative work with Mr. Nakamura, Ms. Sakai and Mr. Kawamoto from BIOAPATITE, INC.

\section{REFERENCES}

[1] Army Corps. of Engineers. (2004). Reuse of Concrete Materials from Building Demolition (Public Works Technical Bulletin 200-1-27). U. S. Department of the Army.

[2] Neville, Adam. M. (2011). Properties of Concrete. Pearson Education Limited

[3] Soroka, I., Peter J. Sereda. (1968). The Structure of Cement Stone and the Use of Compacts as Structural Models. In: 5th International Symposium on the Chemistry of Cement. Tokyo, Japan.

[4] Sakai, Y., Tarekegne, B.T. \& Kishi, T. (2016). Recycling of hardened cementitious material by pressure and control of volumetric change. Journal of Advanced Concrete Technology, 14(2), 4754. https://doi.org/10.3151/jact.14.47

[5] Tarekegne, B. T, Sakai Y. and Kishi, T. (2016). Experimental study of the Compressive Strength and Porosity of Powder Compacted Concrete, Sludge and Cement Paste. In: 11th fib PhD symposium in Civil Engineering. Tokyo, Japan.

[6] Natashah Hitti. (2018, December 12). Rowan Minkley and Robert Nicoll recycle potato peelings into MDF substitute. Dezeen. Retrieved January 9th, 2020, from https://www.dezeen.com/2018/1 2/12/rowan-minkley-robert-nicoll-recycle-potato-peelings-mdf-substitute/

[7] Omid Hosseinaei, David P. H., Joseph J. B., Timothy G. R. (2017, June 27). Improving Processing and Performance of Pure Lignin Carbon Fibers through Hardwood and Herbaceous Lignin Blends. International Journal of Molecular Sciences. https://doi.org/10.3390/ijms18071410

[8] Hamiyet S. K., Yusuf S., Sema A. K. (2015). Effect of heat treatment on the mechanical properties, and dimensional stability of fir wood. In: The XXVII International Conference Research for Furniture Industry. Ankara, Turkey.

[9] Minzhen B., Xianai H., Mingliang J., Neng L., Yanglun Y., Wenji Y. (2018). Study on the changes in surface characteristics of populous tomentosa due to thermo-hydro-process. Journal of Wood Science, 64:264-278. https://doi.org/10.1007/s10086-018-1697-9 